\title{
La agencia de personas con VIH (PV) que viven en zonas empobrecidas de Chiapas, México
}

\author{
The agency of people living with HIV, living in impoverished areas \\ of Chiapas in Mexico
}

\author{
Francisco Chong Villarreal ${ }^{1}$ \\ Centro de Estudios Superiores de México y Centroamérica,
} México

\author{
Teresa Margarita Torres López ${ }^{2}$ \\ Universidad de Guadalajara, México
}

Resumen. Este trabajo tiene por objetivo identificar las dimensiones de la agencia (presente, pasado y futuro) de personas con VIH (PV) en comunidades de Chiapas, México. La agencia es la capacidad para responder a los desafíos que se suscitan en la vida con los recursos que se disponen. Se realizaron 20 entrevistas (12 hombres y 8 mujeres) a personas que viven con el virus (PV) que habían recibido el diagnóstico al menos un año antes de la entrevista; rango de edad 21 a 59 años. Se siguió un guión de preguntas abiertas. Resultados: las PV, participan en la familia extensa para cubrir necesidades que trae el padecimiento. Discusión: Las PV no carecen de poder para enfrentar los desafíos relacionados con la salud y el estigma asociado al VIH.

Palabras clave. VIH, agencia, familia extensa, pobreza.

Abstract. This paper aims to identify the dimensions of the agency (present past and future) in people with HIV (PV) in communities of Chiapas/México. The agency is the capacity to respond to the challenges that arise in life with resources that are available. Twenty interviews were conducted (12 men and 8 women) to people that lve with the virus (PV) who had received the diagnosis at least one year earlier with an age range from 21 to 59 years. A script of open questions followed. Results: PV participate within the extended family to meet the needs of the disease. Discussion: People with HIV do not lack the power to address health challenges and HIV-related stigma

Key words. HIV, agency, extended family, poverty.

${ }^{1}$ Francisco Chong Villarreal. Centro de Estudios Superiores de México y Centroamérica, México. E-mail: momosabio@hotmail.com ${ }^{2}$ Teresa Margarita Torres López. Universidad de Guadalajara, México. E-mail: tere.torres.cucs@gmail.com

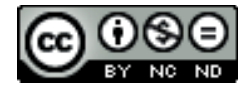

Esta obra está bajo una licencia de Creative Commons Reconocimiento-NoComercial-SinObraDerivada 4.0 Internacional. 


\section{Introducción}

En el proceso de entender o explicar el impacto del Virus de Inmunodeficiencia Humana (VIH) y el sida en la vida de las personas y en el curso de la epidemia misma, ha predominado la perspectiva teórica que enfatiza la determinación de las estructuras sociales sobre la acción de las personas (Sontag, 1996; Parker \& Aggleton, 2002; ONUSIDA, 2007; Earnshaw \& Chaudoir, 2009). El estigma asociado al VIH y sida se destaca como una construcción social que moldea creencias y comportamientos relacionados con la sexualidad, provocando vergüenza, culpa y miedo en quienes no están dentro de la norma social; de este modo, las estigmatizan y condicionan situaciones de discriminación. En esta situación, las personas afectadas por el virus carecen de poder para hacer frente al estigma y sufren sus efectos discriminadores.

Esta visión del estigma asociado al VIH y sida es sistematizada por Parker y Aggleton (2002), quienes plantean un marco teórico que observa su generación dentro de la lógica de poder-dominio; es decir, en un orden social inequitativo y jerarquizado, donde los significados y prácticas son mecanismos de control social.

En esta sistematización se vislumbra una estructura social reificada, dura e inmutable, donde los eventos sociales, aparecen como secundarios o superficiales. En el estigma así comprendido se observa la influencia de nociones como hegemonía (Giacaglia, 2002) y habitus (Capdevielle, 2011).

Tomando en cuenta el potencial negativo del estigma sobre la vida de las personas afectadas por el virus, se han realizado estudios que evidencian su presencia en espacios sociales como hospitales o lugares de reunión de jóvenes y en grupos de la población como personal de salud, jóvenes, entre otros (Comisión Nacional de Derechos Humanos, 2004; Evangelista \& Kauffer, 2007; Infante et al., 2006). También, se han hecho llamados (ONUSIDA, 2007) para crear estrategias cuya meta sea disminuir sus efectos discriminadores.

En contraste con los fundamentos teóricos que contribuyen en la construcción del estigma asociado al VIH y sida, sistematizada por Parker y Aggleton (2002), teóricos de la estructuración (Emirbayer \& Mische 1998; Sewell, 1992) señalan que las personas nunca carecen de poder para hacer frente a las condicionantes estructurales y pueden, incluso, con su acción, realizar cambios en dichas estructuras.

Teoría de la estructuración, marco para comprender la agencia de las $P V$

Dentro de la propuesta de la teoría de estructuración se destacan los conceptos de agencia y estructura, los cuales se refieren a dos aspectos interconectados y dinámicos que definen la acción humana.

Emirbayer y Mische (1998, p. 970) proponen la siguiente definición de agencia:

(...) acción temporalmente construida por actores, quienes se encuentran en diferentes medio ambientes estructurales -contextos donde actúan temporalmente-. Éstos, a través del interjuego de hábito, imaginación y juicio reproducen y transforman estas estructuras en las interactivas respuestas que dan a los problemas que enfrentan en las cambiantes situaciones históricas.

De acuerdo con Emirbayer y Mische (1998), (a) hábito, (b) imaginación, juicio y (c) reproducción o transformación de las estructuras, constituyen tres dimensiones de la agencia, que se expresan simultáneamente. De manera respectiva, estas dimensiones corresponden (a) al pasado conformado por los elementos habituales de la agencia; (b) el presente, o las circunstancias que cotidianamente experimentan y que activan la imaginación y el juicio de las personas; y (c) el futuro, esto es, la realización o imaginación de estrategias para responder a los desafíos, miedos o metas que surgen ante los desafíos, donde la respuesta se articula con el bagaje de posibles respuestas dentro de su contexto.

La agencia no es una acción independiente de la cultura, en tanto las personas reciben de ahí, modelos de pensamiento y acción con los cuales articularán su acción. Esta última esta mediada por la reflexión y evaluación de las personas quienes eligen entre las alternativas que les están disponibles en su marco estructural. 
Sewell (1992) ofrece una concepción de estructura que permite apreciar de manera más operativa los componentes y posibilidades de la agencia. Para él, una estructura tiene una composición dual, porque está conformada de esquemas y recursos que se implican y sostienen entre sí, en el tiempo. Los recursos son medios para conseguir o conservar poder y son inequitativamente distribuidos. Hay recursos humanos como la fuerza física, la destreza, el conocimiento, un puesto administrativo o político, el compromiso emocional, etc. También, los hay no humanos, que pueden ser animados o inanimados, como una fábrica, los animales, el dinero, etc.

Los esquemas, por su parte, son procedimientos que se aplican en la realización o reproducción de la vida social, como las reglas de etiqueta, las normas estéticas, las recomendaciones que se hacen para el progreso social, las costumbres, etc. Es decir, no son procedimientos que se derivan nada más de prescripciones formalmente escritas, en tanto incluye también aquellos informales y no siempre conscientes como los que se establecen en la cultura, donde se desprenden los procedimientos que se deben llevar a cabo según el sexo de las personas. Estos procedimientos, generalmente, se forman casi de forma imperceptible, como a través de los juegos infantiles (por eso se utiliza el término esquema en lugar de regla).

La agencia, como respuesta innovadora, es posible porque los sujetos encuentran alternativas dentro de las sociedades fragmentadas en que se encuentran. Son fragmentadas en el sentido de que están compuestas de múltiples estructuras ubicadas en diferentes niveles (Sewell, 1992; Sautu, 2014; Emirbayer \& Mische, 1998). Así, se puede pensar que las PV, además de formar parte de una familia y una comunidad de donde reciben esquemas y recursos, participan, en ocasiones, en otros espacios (como la escuela, hospital, cooperativa, etc.) que tienen sus propias configuraciones estructurales. La participación de esta multiplicidad de estructuras alimenta la reflexión y favorece respuestas innovadoras y creativas a desafíos, metas y miedos experimentados en la cotidianidad.
Lo anterior no significa que la agencia genere una ruptura abrupta entre la acción humana y el contexto socio-cultural, como acotan Emirbayer y Mische (1998). Más bien, los actores humanos no solamente repiten rutinas pasadas; son también inventores de nuevas posibilidades para pensar y actuar, aprovechando los esquemas y recursos disponibles. Clarifican motivos, metas e intenciones. Localizan posibles obstáculos e identifican cursos de acción que sean moral y prácticamente posibles. En este proceso, las estrategias imaginadas no se realizan de una vez y para siempre, sino que están sujetas a continuas reevaluaciones.

A fin de explorar el potencial de las PV en el aprovechamiento de los recursos y esquemas con que cuentan para responder creativamente a desafíos que vienen con el diagnóstico, se propone este trabajo cuyo objetivo es identificar las tres dimensiones de la agencia (presente, pasado y futuro) de PV que residen en comunidades de Chiapas.

\section{Método}

Para el análisis de la agencia de las PV, se utilizaron 20 entrevistas (12 hombres y 8 mujeres) realizadas de abril a agosto de 2010 (tabla 1). Las edades de las personas entrevistadas tienen un rango de los 21 a los 59 años, con un promedio de edad de 36 años. Las entrevistas se hicieron en uno de los dos centros de atención que, dentro de la Jurisdicción Sanitaria VII, son encargados de atender a personas con VIH en la región del Soconusco, en el estado de Chiapas.

Se siguió un guión de preguntas abiertas que pretendía recoger las estrategias seguidas por las personas para enfrentar situaciones que el VIH trajo consigo. Entre las preguntas realizadas estaban las siguientes: ¿Cómo se enteró que tenía VIH? ¿Cómo reaccionó cuando le dieron el diagnóstico? ¿Quiénes estaban con usted? ¿Qué pensamientos cruzaron por su cabeza?, entre otras. Dependiendo de las respuestas, se fueron profundizando los temas en cada persona. Se privilegiaron aquellos relacionados con la familia, el trabajo y la comunidad. Cuando salió el tema de la comunidad, y dependiendo si había o no rumor del padecimiento entre familiares o vecinos, se hicieron 
Tabla 1

Datos generales de informantes

\begin{tabular}{|c|c|c|c|c|c|}
\hline Sexo & Edad (años) & Tiempo de diagnóstico (años) & Número de hijos & Estado civil & Escolaridad \\
\hline \multirow[t]{8}{*}{ Mujeres } & 31 & 7 & 1 & unión libre & cuarto de primaria \\
\hline & 40 & 5 & 7 & casada & 0 \\
\hline & 34 & 7 & 2 & viuda & tercero de secundaria \\
\hline & 28 & 4 & 2 & viuda & tercero de preparatoria \\
\hline & 26 & 6 & 2 & viuda & tercero de secundaria \\
\hline & 23 & 1 & 2 & casada & 0 \\
\hline & 59 & 7 & 5 & divorciada & tercero de primaria \\
\hline & 50 & 4 & 3 & unión libre & tercero de primaria \\
\hline \multirow[t]{12}{*}{ Hombres } & 55 & 6 & 0 & soltero & tercero de secundaria \\
\hline & 42 & 3 & 0 & soltero & sexto de primaria \\
\hline & 48 & 3 & 0 & soltero & tercero de primaria \\
\hline & 28 & 1 & 0 & soltero & tercero de preparatoria \\
\hline & 28 & 4 & 0 & soltero & tercero de secundaria \\
\hline & 42 & 4 & 1 & soltero & sexto de primaria \\
\hline & 40 & 5 & 7 & casado & cuarto de primaria \\
\hline & 27 & 1 & 2 & casado & 0 \\
\hline & 27 & 9 & 1 & soltero & segundo de secundaria \\
\hline & 21 & 6 & 0 & casado & tercero de preparatoria \\
\hline & 38 & 3 & 2 & viudo & tercero de secundaria \\
\hline & 33 & 2 & 1 & separado & tercero de secundaria \\
\hline
\end{tabular}

preguntas como las siguientes: ¿Cómo reaccionaron en la comunidad? ¿Qué hizo frente a los rumores? Todas las personas informantes habían recibido el diagnóstico al menos un año antes de la entrevista. Se contó con el apoyo del médico internista y de una psicóloga y un psicólogo del centro hospitalario. Las entrevistas se llevaron a cabo en el cubículo destinado al área de psicología. La persona que realizó las entrevistas tiene como antecedente haber colaborado en una asociación civil cuyo tema de trabajo es el VIH (atención, prevención, consejería pre y pos prueba). Para conformar la muestra, se inició invitando a personas que asistían a consulta; también, se incluyeron a otras que fueron invitadas por las primeras. El criterio de inclusión fue que las personas participaran voluntariamente y tuvieran al menos un año de haber recibido el diagnóstico. El consentimiento informado fue grabado al inicio de cada entrevista.

Las entrevistas fueron grabadas y transcritas. Para el análisis se utilizó el programa Atlas.ti (Friese, 2014). Se realizó una codificación organizado alrededor de categorías analíticas (condiciones de vida, vivencia del estigma, silencio del estigma, familia), que permitieron ir comparando las entrevistas. También, se hicieron categorías descriptivas (edad, sexo, estado civil, número de hijos). Para entender la agencia de las personas se recurrió al método de comparación constante (Boieje, 2002), que establece que las categorías son creadas mientras se comparan las entrevistas. De esta manera se encuentran aspectos constantes y conexiones que ayudan a explicar el fenómeno estudiado. 
Para garantizar la validez y confiabilidad de la recolección y análisis de los datos, una triangulación (entendida como la combinación de aproximaciones de investigadoras-es) de quienes participaron en discusiones en torno al proceso y el resultado del análisis (Flick, 2014). Esto se llevó a cabo en espacios académicos. Además, los autores realizaron el análisis en forma separada, llegando a los mismos resultados.

\section{Notas sobre el contexto de estudio}

En los últimos años, en el estado de Chiapas, se ha incrementado la tasa de personas afectadas por el VIH y sida; pasó del quinceavo lugar, con 126 personas (COESIDA, 2011) al onceavo sitio (CENSIDA, 2015) con 213 personas por cada 100000 habitantes. Del total de casos (CENSIDA, 2013), el 71\% corresponde a hombres y el resto a mujeres.

Por otra parte, en la región del Soconusco, desde finales del siglo XX (Santacruz de León \& Pérez, 2009) se observa un incremento de la migración de personas locales atraídas hacia ciudades importantes del estado (Tapachula, Huixtla y Tuxtla Gutiérrez). A la vez, se observa una inmigración de centroamericanos, hombres y mujeres, que llegan a cubrir las necesidades de mano de obra en el campo agrícola y en el trabajo doméstico.

En relación con el VIH y sida, en esta región se han realizado estudios que señalan la carencia de poder de las personas sobre las fuerzas estructurales que condicionan la vulnerabilidad social frente al VIH, especialmente en grupos de jóvenes, migrantes, indígenas y trabajadoras sexuales (Evangelista \& Kauffer, 2007; Leyva \& Quintino, 2011; Villa et al., 2004; García, Meneses \& Palé, 2007) .También, se ha explorado la capacidad innovadora de la agencia en personas con VIH (Chong-Villarreal, Fernández, Huicochea, Álvarez \& Leyva, 2012; Chong-Villarreal, Fernández, Huicochea, Álvarez \& Leyva, 2014), pero sin profundizar en el vínculo de esta innovación con el pasado (los recursos culturales con los que se cuenta para la agencia).

Las personas entrevistadas para este estudio provienen de diferentes municipios del Soconusco, cuyos recursos los obtienen del trabajo informal (cargador de bultos, limpieza, encargados de bares, vendedores ambulantes, etc.). La mayoría de las mujeres, aunque se dicen amas de casa, durante las entrevistas dejan entrever que participan también en los negocios familiares (cuando existen), incluso ocasionalmente también en actividades del campo.

\section{Resultados}

Los resultados que a continuación se presentan fueron agrupados en las dimensiones de la agencia (pasado, presente y futuro), así como una categoría emergente sobre los ajustes estructurales al interior de la familia extensa. Los ejes temáticos son: (a) La dimensión del pasado en la agencia. La familia extensa; (b) Presente y futuro de la agencia. El impacto del diagnóstico y la lucha por sobrevivir: redefiniendo el pasado; (c) Los ajustes estructurales para seguir integrados en la familia extensa. El silencio, un recurso para la sobrevivencia.

\section{La dimensión del pasado en la agencia. La familia extensa}

Para este y los dos siguientes apartados, se considera la propuesta de Emirbayer y Mische (1998), quienes afirman que la agencia está formada de tres dimensiones simultáneamente; la primera, denominada dimensión del pasado de la agencia, conformada por los hábitos y prácticas culturales. En ese sentido y con relación a este trabajo, las PV refieren ser parte de un grupo familiar, donde se establece una dinámica que les permite resolver, en cierto grado, sus necesidades materiales de sobrevivencia.

Esos grupos familiares no solo están conformados de padres e hijos, ya que tienen la suficiente maleabilidad y flexibilidad para reinsertar a miembros que se habían marchado e integrar a otros, no necesariamente consanguíneos. El siguiente relato corresponde a un hombre que recientemente se casó y su esposa se ha integrado a la familia. Él, además, comentó que sus padres, quienes actualmente están separados, migraron a Estados Unidos. La madre sigue apoyándolo a él y a sus hermanos con dinero que les envía con frecuencia. El padre no ha podido ayudarlos, porque es alcohólico. 
Soy campesino, chaporreando el potrero, mi abuelito es el dueño, él me da trabajo. Eso he hecho desde pequeño. Nunca he hecho otra cosa. En otro lado no he trabajado. Vivo con mis abuelitos todavía, una mi tía y mis tres hermanos. Somos cinco, pero uno está casado y ya no vive con nosotros. Está el otro que sigue es más grande que yo, después sigue yo, y mis dos hermanitas, más pequeñas que yo, una tiene 15 y otra 18. Una estudia la secundaria y otra la prepa... No le pagamos la renta a mi abuelito, pero él nos paga para trabajar... Siempre no alcanza, pero ahí la vamos pasando. A veces tengo que comprar una pastilla. Apenas me enfermé. Gracias a Dios que mi abuelito siempre nos ha apoyado. Ellos nos dan la comida, nosotros no gastamos en comida. (21 años).

Presente y futuro de la agencia. El impacto del diagnóstico y la lucha por sobrevivir: redefiniendo el pasado

Las posibilidades para reproducir o transformar estructuras (esquemas y recursos) se abren en los sucesos cotidianos que se experimentan cuando los recursos y esquemas tienen que ser sopesados: se seleccionan y se adecúan. Se arman estrategias para responder a los desafíos que se presentan. Es la dimensión del presente y futuro de la agencia.

El diagnóstico (y en ocasiones la enfermedad), al irrumpir en la cotidianidad de los sujetos, potencia las posibilidades de experimentar la discriminación de la familia y la comunidad, amenazando el acceso a una fuente de apoyo importante para cubrir necesidades materiales: la familia extensa. Las personas recurren a esa conformación familiar cuando, además, requieren de recursos materiales para atenderse en el hospital.

Entre las consecuencias que vienen con el VIH y el sida está la pérdida del trabajo por incapacidad o por efecto del estigma o la muerte de uno de los cónyuges (en el caso de las parejas). Cuando la muerte es de quien proveía los recursos materiales para vivir, para quien sobrevive, se plantea la necesidad de obtenerlos por su cuenta.

Regresar al ámbito familiar y participar de la dinámica de colaboración constituye una posibilidad para disminuir los costos de alimentación y vivienda. Una mujer que enviuda y se queda con dos hijos comenta que ella se dedica a la venta de diferentes productos en la escuela de sus hijos y con sus vecinos:

(...) yo vivo con mi papá, su mujer y mis niños. Solo ellos. (¿Quién mantiene la casa?) Mi papá. Pues mi papá trabaja y le da su gasto a ella. Digamos que los dos (el padre y ella), porque nos compartimos los gastos. $\mathrm{Si}$ vamos a comprar gas, entra las dos (la madrastra y ella). Si vamos a pagar luz, entre las dos. Si vamos a comprar una comidita, entre las dos: tú pones tal cosa y yo tanto. Ella, su mujer y yo llegamos a un acuerdo: si vamos a comprar una cosa, "ah está bien". Ya lo que es de mi hijos, solo yo. (34 años).

Además de las estrategias de colaboración para disminuir los costos materiales para vivir, la familia, en ocasiones, también genera sus propios recursos. El siguiente es un comentario de un hombre, quien emigró a Estados Unidos para conseguir dinero con el cual pudo completar para comprar un terreno más fértil y más accesible a mercados donde puede vender su cosecha:

(...) hay producto que no lo acabamos de consumir ni lo podemos vender ¿Por qué? Porque nos cuesta la sacada. Entonces a comparación de donde vivíamos eso me hace ser feliz; porque cuando viene un mi familiar, mi vecino, alguien por lo regular de la familia de allá, en lugar que compra, lo lleva de regalado. Porque allá, para que nosotros chupáramos un mango, teníamos que salir, comprarlo. Era difícil pues. (40 años).

Un aspecto que parece favorecer la flexibilidad de este tipo de familias para integrar a otros miembros es la participación en actividades que allí se realizan. Puede ser desde la limpieza de la casa hasta el cuidado de personas mayores o enfermas, pasando por la colaboración en el negocio familiar, cuando existe. Un ejemplo de esto lo proporciona un hombre que fue dado de baja en el ejército mexicano. Mientras el padre se dedica a la producción de café, la madre le ofrece la posibilidad de trabajar con ella. Esto se dio después de un tiempo de haber trabajado en una tortillería y en la construcción de una carretera por periodos cortos.

Mi mamá siempre vendía, me dijo; "¡échame la mano!, a ti que te gusta andar con la moto, que te gusta andar carrereando”, “¿porque no vendes?” 
Siempre tenía amigos en los restaurantes, con las señoras. Ahorita nada más nos llaman por teléfono nos dicen "quiero tanto de pollos", vengo corriendo, con la moto. ¿En qué lugar lo quieres? (27 años).

El comercio informal es un recurso importante para complementar los ingresos en la familia; pero también, cuando no hay otros ingresos, el negocio familiar es la única posibilidad. Una mujer compartió que al enviudar por complicaciones del sida, se muda a la casa de su padre donde, además, viven otros hermanos. Su padre había perdido su empleo y también cuida a su abuelo enfermo. En el caso de esta familia, la alternativa fue comprar, con el dinero de la liquidación en el anterior trabajo del padre, un carrito para vender hot dogs, en la vía pública.

(Para cuidar a su abuelito, su papá)...dejó su negoció de él. Lo agarré yo. Pero nos ayudamos ambos, no me da una cuota así semanal, pero de lo que vendemos, si necesito dinero, de allí mismo lo agarro. Cuando necesito dinero, le pido: ¡necesito tanto!; pues él me lo da. Así lo vamos trabajando, entre los dos. (28 años).

Dentro del grupo de informantes, hay un hombre que enviuda y pierde su trabajo de cargador de café. En ese momento, él no había emprendido ningún negocio. Para sobrevivir, invita a sus hijos pequeños a vender elotes hervidos.

(En relación con sus hijos:) Ahorita cada quien lava su ropa, lavan ellos. Yo, al principio se los hacía yo. Pero ahorita les dije cada quien va a lavar su ropa... Para que salgan adelante, pue. Que le echen ganas a trabajar a que aprendan a trabajar también, sino después van a sufrir ellos. Por eso cuando no hay clases, el más grande sale a trabajar. Él más grande sale a trabajar, el otro ya le gusta el negocio. "Chambeando mijo hay dinero", le digo. Andan su dinero en la bolsa. (¿Les das dinero a ellos?) Yo no, de lo que ganan pue, de los elotes, una tanda él y otra para comer. Al más chico, anda su dinerito pue. (Eso sucedió)... A partir de que tengo $\mathrm{VIH}$, porque antes se los daba todo. Antes llegaba, todo se lo daba, y a mi esposa le daba lo que quería. Ella lo repartía con los chamacos, cuando iban a la escuela. Ahorita ya no, "hay que ganarse el dinero, mijo, para que veas como cuesta. Que vender no es vergüenza, robar sí”.
(¿Quién tomó la decisión del negocio?) Yo les pregunté a ellos, si querían vender, a los dos. ¡Vendemos!, me dijeron. Y vamos hacer esto, les dije, una tanda para ti, una para mí y la otra para el más grande. Una cada uno. (38 años).

Las dificultades para resolver las necesidades materiales se encuentran en todas las familias de este contexto. Las personas tienden a implementar estrategias de organización y distribución de los recursos que no son en su mayoría económicos. Una mujer, quien además del trabajo del esposo y contar con el apoyo de su padre para sobrevivir, comparte lo siguiente:

..., cuando ya no tenemos, a veces vamos a juntar verdura, a veces hay chipilín. Si somos inteligentes, regamos el chipilín. Regamos el bledo. Sembramos chayote. Sembramos el frijol triple que se da. Pues lo ponemos a guisar. Chipilín guisado. Yerbamora en caldo. El año pasado sembramos frijol. Todavía nos queda poquito. El año pasado, sembramos un poquito de milpa con mi papá, que nos hace el favor de sembrarlo allá. La cosechamos. Tenemos maíz un poquito. Con eso la pasamos. No con dinero en la bolsa, aquí nomás tengo mi pasajito, 20 pesos; $9 \mathrm{mi}$ esposo, 9 yo. Con eso ya llegamos. Eso es. Y ya, pues no podemos tener los 500. 2000 pesos en la bolsa. No lo tenemos. (40 años).

Dentro del grupo de hombres, tres, además de las actividades que habían realizado para vivir (limpieza o encargados de bares), con frecuencia se travestían y ejercían el comercio sexual. Dos de ellos, después de haber recibido su diagnóstico, han tenido más dificultades para encontrar trabajo remunerado. Viven con padres en edades avanzadas y sus familias no cuentan con un negocio propio. Cuentan con apoyo de familiares que no viven con ellos, amigos o vecinos, quienes a veces aportan con productos del campo o alimentos procesados, como mango, chipilín, etc. El recurso proveniente de programas gubernamentales, como Amanecer, 60 y más, Oportunidades, es un apoyo importante. En estos casos, es más notaria que en el resto de personas entrevistadas, la dificultad para adquirir recursos económicos que destinar a alimentación y transporte. Para ilustrar lo anterior, se comparte el testimonio 
de un hombre quien, para sobrevivir, en ocasiones intenta administrar una cantina, pero parece que tiene dificultades, ya que no mantiene el empleo. Cuando se le preguntó quién le proporcionaba recursos para vivir, respondió lo siguiente:

Mi mamá de que le dan su paguita de oportunidad del gobierno (programa gubernamental). Mi mamá es la que más gasta. Mi papá no gasta, es muy codo. Aquel día que vine yo para acá, el 12 de mayo, me dijo "ten mijo para tu refresco". Yo lo acepté, siete pesos, nada más. ¿Qué me va alcanzar? mire nada más. Yo no dije nada más. Una hermana me regaló 12 pesos. El camión cobra casi 12 pesos de ida y otro de vuelta. Ahorita porque nada más tenía un rescoldito, que me quedó todavía. Con esto vengo yo, con eso me alcanza... Una hermana que tengo acá en Huixtla, ella es la que me regala mis 100 pesos cada tres semana o cada dos semanas y media. Si yo quiero mi pasta dental, mi shampoo, alguna cosa, mi hermana me lo compra a mí. Aunque sea mi ropita que traigo. Una mi amiga en Mapa (comunidad chiapaneca) me compró mis zapatitos... (48 años).

Los ajustes estructurales para seguir integrados en la familia extensa. El silencio, un recurso para la sobrevivencia

Las PV comparten el temor de ser discriminadas, en la familia y la comunidad, por el diagnóstico del VIH; un temor imaginado y en ocasiones experimentado. Algunas PV han vivido la discriminación en el trabajo y con algunos familiares. Generalmente, solo comparten su diagnóstico con algunos familiares. Se crea un subgrupo dentro de la familia extensa: el de quienes conocen el diagnóstico y validan el silencio como estrategia para seguir unidos en el grupo extenso.

Un hombre que intentó trabajar en la policía municipal dice que desechó esa opción cuando le pidieron análisis de sangre. Él compartió con sus padres el diagnóstico y les pidió que no lo hicieran extensivo a sus seis hermanos “... con nadie, la gente empieza a divulgar, a decir cosas. Hacen sentir a uno mal también, es mejor así... Empiezan a divulgar a alejarse más de uno" (27 años). Una mujer, madre de siete hijos y quien dice que no asistió a la escuela, tiene una postura similar. Comenta que es selectiva al momento de informar sobre su diagnóstico con su familia. Al respecto, relata: "Bueno, y si lo platico, pero será mi papá, será mi mamá, será mi hermano, una hermanita, pero de confianza. Menos, aunque sea mi otra hermana, que sepa que no detiene la lengua a veces. Pues no se la cuento" (40 años).

Las personas a quienes se comparte la información dentro de la familia también favorecen ese silencio hacia algunos familiares y sobre todo a personas fuera de la familia extensa. Un hombre ilustra esa situación como sigue:

..., los niños, nuestros hijos, todos saben. Pero ellos son igual que nosotros, de allí no sale nada, no pase nada... Nos apoyan, nos ayudan. Dicen "hoy van a tener plática. Hoy vas a ir al hospital, o tal día te toca. Ponte listo. Ya es hora: jvayen ya!" (sic). Entonces ellos nos apoyan en lo que nosotros realizamos, en lo que nosotros hacemos... Ellos también han sabido, que en los problemas de salud, a veces hay discriminación. Y siempre ellos se ponen a platicar solos... (40 años).

\section{Discusión}

La noción de estructura puede asociarse a la idea de construcción social ajena a los individuos, porque está antes y después de ellos, pero ordena sus pensamientos y acciones. Partiendo de esa idea de estructura, dura e inmutable, con capacidad para mantener a las personas dentro de estrechos marcos de pensamiento y acción, se ha sistematizado el estigma asociado al VIH y sida (Parker \& Aggleton, 2002) con aportes de influyentes pensadores como Bordieu (Capdevielle, 2011), Foucault (1998) y Gramsci (Giacaglia, 2002).

En la sistematización, se destacó el potencial del estigma para agravar tanto la epidemia como para dañar a las personas afectadas por el virus. El estigma construido en la lógica del poder-dominio, apuntaló normas ya existentes en el terreno de la sexualidad, alineadas en tres aspectos fundamentales: la heterosexualidad, la sexualidad con fines de reproducción y el matrimonio heterosexual. El VIH y sida, quedó asociado a lo que estaba fuera de esa norma. Ante ese orden, para las PV, solo se puede imaginar exclusión social y la muerte. 
Sin embargo, los seres humanos son agentes empoderados por el acceso a recursos y esquemas de diverso tipo, acotarían teóricos de la estructuración (Sautu, 2014; Emirbayer \& Mische, 1998; Sewell, 1992; Morawska, 2007). Estos pueden, de alguna manera, eludir los condicionamientos estructurales y, en cierto grado, realizar cambios en dichas estructuras. Considerando las estructuras sociales, como lo propone Sewell (1992), conformadas con recursos y esquemas, y a las sociedades fragmentadas por la coexistencia de múltiples estructuras en diferentes niveles; se ha realizado el análisis, partiendo del reconocimiento del poder de las estructuras (recursos y esquemas) para moldear la vida de las PV. También, se observó la capacidad de agencia de estas PV en el manejo de los recursos y esquemas disponibles en su medio estructural, para desarrollar estrategias que cubren necesidades negadas en la construcción social que se ha hecho del VIH.

La agencia - dirían Emirbayer y Mische (1998) - no es una respuesta mecánica, sino una acción mediada por la reflexión y motivada por miedos, proyectos y deseos que se presentan en la cotidianidad de la vida. En esa lógica, las PV arman, ante las necesidades materiales y las amenazas de exclusión social, estrategias de sobrevivencia. Apelan a lo que tienen en la cultura, la familia extensa (Enciclopedia Británica en Español, 2009), sustentada en la colaboración entre sus miembros (consanguíneos y no). La familia extensa ha sido un recurso ancestral que persiste en diferentes regiones de México (Robichaux, 2002; Davinson, 2007; Mindek, 2007) afectadas por la pobreza extrema. La forma en que se organizan las familias extensas constituye un recurso disponible para cubrir las necesidades materiales y es reactivado o modificado por las propias personas o sus familiares, para enfrentar los desafíos que el VIH trae; como la madre que le sugiere al hijo que se integre a su negocio de pollos. La reactivación de la familia se observa, incluso, en casos donde se complica la obtención de recursos porque no hay un negocio familiar o por vejez de padres.

Retomar elementos culturales como la familia extensa, no se da sin adecuaciones; por eso, su implementación es una respuesta novedosa. Estas adecuaciones permiten soslayar la discriminación que no es solo imaginaria sino también una posibilidad constatada por algunas personas entrevistadas y que ya se ha documentado previamente (ONUSIDA, 2005; Juárez, 2016). Para estas personas, la discriminación es una amenaza real. En las condiciones en que se encuentran, la difusión amplia de un diagnóstico podría traer marginación, que se expresaría en un incremento de las dificultades para la sobrevivencia. En ese sentido, el silencio selectivo en torno al diagnóstico es una respuesta reflexionada para evadir mayores dificultades que la discriminación acarrearía. Hay un trabajo previo (Chong-Villarreal et al., 2012), que profundiza en el silencio y la negación del diagnóstico en la comunidad y con algunos familiares. En estos casos, generalmente el diagnóstico solo es compartido con algunos miembros de la familia. En ese texto, se señala que este grupo informado proporciona apoyo tanto emocional, como también, para cumplir con las prescripciones médicas.

Entonces, se destaca de las entrevistas que las personas no están carentes de poder, activan los recursos que disponen en los diferentes medio ambientes socioculturales y articulan respuestas. La familia extensa como recurso para enfrentar necesidades que vienen con el VIH ha sido ya explorada en otro trabajo (Chong-Villarreal et al., 2014). Sin embargo, a diferencia de ese trabajo, en este se presentan las tres dimensiones de la agencia que proponen Emirbayer y Mishe (1998), lo que metodológicamente permite abordar la agencia en una más compleja dinámica con las estructuras. Considerar las dimensiones del pasado, presente y futuro, permite constatar que las estructuras, sin bien moldean prácticas y pensamientos, forman también parte de la agencia como recursos y esquemas que podrán recrearse o replantearse en la acción de las PV.

La agencia para responder a los desafíos que las PV enfrentan debería tener implicaciones en el abordaje y tratamiento de los efectos del estigma sobre las PV. Parker y Aggleton (2002) destacan las enormes fuerzas sociales envueltas en la generación y reproducción 
del estigma; hacen hincapié en la necesidad de hacer intervenciones estructurales dirigidas a reducir la estigmatización y la discriminación que de ahí se deriva.

A pesar de todo lo anterior, la situación así presentada es incompleta si no se considera la agencia social. La agencia no es un elemento irrelevante, las personas la implementan logran resolver algunos requerimientos que, de no cubrirse, empeorarían su situación de salud. Por otro lado, no valorar la agencia puede contribuir a revictimizar a las personas con VIH, al presentarlas como carentes de poder para reaccionar al virus. Con ello, se fomenta la percepción de una PV con imágenes degradantes, similares a las metáforas de terror que se generaron al inicio de la epidemia (Sontag, 1996), donde se comparaba al sida con la muerte, la soledad y el abandono, y que contribuyeron con el estigma asociado al VIH y sida.

\section{Referencias}

Boieje, H. (2002). A purposeful approach to the constant comparative method in the analysis of qualitative interviews. Quality and Quantity, 36(4) 391-409.

Capdevielle, J. (2011). El concepto de habitus: Con Bourdieu y contra Bordieu. Andulli. Revista Andaluza de Ciencias Sociales, 10(20), 31-45.

Centro Nacional para la Prevención y el Control del VIH/Sida (CENSIDA). (2015). Panorama de la respuesta nacional al VIH, México. Recuperado de http://www.gob.mx/cms/uploads/attachment/ file/31880/Panorama nacional_de la respuesta a la epidemia de VIH2015.pdf.

Centro Nacional para la Prevención y el Control del VIH/Sida (CENSIDA). (2013). Vigilancia epidemiológica de casos de VIH/SIDA en México. Registro nacional de casos de Sida. Actualización al 30 de junio de 2013. Recuperado de http://www. censida.salud.gob.mx/descargas/epidemiologia/ RN 2o trim 2013.pdf.

Chong-Villarreal, F., Fernández, C., Huicochea, L., Álvarez, G. C., \& Leyva, R. (2012). Estrategias de personas con VIH para enfrentar el estigma asociado al VIH/Sida. Pacientes del Hospital
General de Huixtla, Chiapas. Estudios Fronterizos, nueva época, 13(25), 31-56.

Chong-Villarreal, F., Fernández, C., Huicochea, L., Álvarez, G. C., \& Leyva, R. (2014). Estrategias familiares de hombres y mujeres con VIH que buscan atender necesidades materiales en la región del Soconusco, Chiapas. Revista Liminar. Estudios Sociales y Humanísticos, 12(1), 177-192.

Comisión Nacional de Derechos Humanos. (2004). Recomendación general no 8/2004. Sobre el caso de la discriminación en las escuelas a menores portadores de VIH o que padecen SIDA. México, D. F.; a 17 de septiembre del 2004. Recuperado de http://www.censida.salud. gob.mx/descargas/recomdagral8.pdf.

Consejo Estatal para la prevención del Sida Chiapas (COESIDA). (2011). Situación del VIH/SIDA en el estado de Chiapas. Tarjetas ejecutivas. Tuxtla Gutiérrez, México: Instituto de Salud del Estado de Chiapas.

Davinson, L. G. (2007). Una mirada al método genealógico y un ejemplo de su aplicación en un pueblo de Tlaxcala, México. En D. Robichaux, comp. Familia y Diversidad en América Latina. Estudios de casos (pp. 164-185). Buenos Aires, Argentina: CLACSO Consejo Latinoamericano de Ciencias Sociales.

Earnshaw, V. A., \& Chaudoir, S. R. (2009). From Conceptualizing to Measuring HIV Stigma: A review of HIV Stigma Mechanism Measures. AIDS Behavior, 13(6), 1160-77.

Emirbayer, M., \& Mische, A. (1998). What is agency? American Journal of Sociology, 103(4), 962-1023.

Enciclopedia Británica en Español. (2009). Enciclopedia Británica en Español. La familia: concepto, tiposy evolución. 2009. Recuperado de http://cvonline.uaeh.edu.mx/ Cursos/BV/S0103/Unidad $\% 204 /$ lec $42 \mathrm{LaFam}$ ConcTipyEvo.pdf.

Evangelista, A., \& Kauffer, E. (2007). Contextos de vulnerabilidad en comunidades de la Región Fronteriza de Chiapas. En R. Tinoco, M. Martínez, y A. Evangelista, A., editores. Compartiendo saberes sobre 
VIH/Sida en Chiapas (p. 77-98). México, México: El Colegio de la Frontera Sur.

Flick, U. (2014). La gestión de la calidad en investigación cualitativa. Madrid: Ediciones Morata.

Foucault, M. (1998). Historia de la sexualidad I, La voluntad de saber. México: Siglo XXI editores.

Friese, S. (2014). Qualitative data analysis with ATLAS.ti. London: Sage editors.

García, J. C., Meneses, S., \& Palé, S. (2007). Migración internacional indígena y vulnerabilidad ante el VIH/SIDA. Los chamulas entre barras y estrellas. Revista Liminar. Estudios Sociales y Humanísticos, 5(1), 119-144.

Giacaglia, M. (2002). Hegemonía, concepto clave para pensar la política. Tópicos, 10,151-159.

Infante, C., Zarco, A., Cuadra, S., Morrison, K., Caballer, M., Bronfman, M., \& Magis, C. (2006). El estigma asociado al VIH/SIDA. El caso de los prestadores de servicios de salud en México. Salud Pública de México, 48(2), 141-150.

Juárez, B. (01 de marzo de 2016). Mexicanos excluyen 'fuertemente' a personas con VIH: CONAPRED. Periódico la Jornada. Recuperado de http:// www.jornada.unam.mx/ultimas/2016/03/01/ mexicanos-excluyen $201 \mathrm{cfuertemente} 201 \mathrm{~d}-\mathrm{a}-$ personas-con-vih-conapred-5427.html

Leyva, R., \& Quintino, F., editores. (2011). Migración y salud sexual y reproductiva en la frontera sur de México. México: Instituto Nacional de Salud Pública.

Mindek, D. (2007). Disolución de parejas conyugales en un pueblo mexicano: ¿divergencia del modelo tradicional? En D. Robichaux, comp. Familia y Diversidad en América Latina. Estudios de casos, (pp. 189-211). Buenos Aires, Argentina: CLACSO Consejo Latinoamericano de Ciencias Sociales.

Morawska, E. (2003). National Identities of Polish (Im)Migrants in Berlin, Germany: Four Varieties, Their Correlates, and Implications," In: W. Spohn, \& A. Triandafyllidou. Europeanisation, National Identities and Migration: Changes in Boundary
Constructions Between Western and Eastern Europe, (pp. 173-92). London: Routledge.

Parker, R., \& Aggleton, P. (2002). Estigmay Discriminación relacionados con el VIH/SIDA: Un marco conceptual e implicaciones para la acción. Documentos de Trabajo No. 9. México: El Colegio de México.

Programa Conjunto de las Naciones Unidas sobre el VIH/Sida (ONUSIDA). (2007). Reducir el estigma y la discriminación por el VIH: una parte fundamental de los programas nacionales del sida. Recurso para las partes interesadas en la respuesta al VIH en los diferentes paises. Recuperado de http://www. cndh.org. mx/sites/all/doc/Programas/VIH/ OtrasPublicacionesdeinteresrelacionadosconelVIH/ Onusida/reducir $\% 20 \mathrm{el} \% 20$ estigma $\% 20 \mathrm{y} \% 201 \mathrm{a} \% 20$ discriminacion $\% 20$ por $\% 20 \mathrm{el} \%$ 20VIH.pdf.

Programa Conjunto de las Naciones Unidas sobre el VIH/Sida (ONUSIDA). (2005). Violaciones de los derechos humanos, estigma y discriminación relacionados con el VIH. Estudio de caso de intervenciones exitosas. Colección Prácticas ópticas del ONUSIDA. Recuperado de http://www.ministeriodesalud. go.cr/gestores en salud/derechos $\% 20$ humanos/ sida/violacionesddhh.pdf.

Robichaux, D. (2002). El sistema familiar mesoamericano y sus consecuencias demográficas: un régimen demográfico en México indígena. Papeles de Población, 8(32), 59- 95.

Santacruz de León, E., \& Pérez, E. (2009). Atraso económico, migración y remesas: el caso del Soconusco, Chiapas, México. Convergencia, 16(50), 57-77.

Sautu, R. (2014). Agencia y estructura en la reproducción y cambio de las clases sociales. Revista theomai. Estudios críticos sobre sociedad y desarrollo, 29, 100-121.

Sewell, W. (1992). A theory of Structure: Duality, Agency, and Transformation. American Journal of Sociology, 98(1),1-29.

Sontag, S. (1996). La enfermedady sus metáforas. El sida y sus metáforas. Madrid: Taurus. 
Villa, B., Tapia, A., Caballero, M., Dreser, A., Cuadra, S., González, T., Leyva, R., Guerrero, C., \& Bronfman, M. (2004). México, Ciudad Hidalgo, Chiapas. En: M.
Bronfman, R. Leyva, \& M. Nigroni. coord. Movilidad poblacionaly VIH/Sida (p. 275-302). México: Instituto Nacional de Salud Pública.

Recibido: 22 de febrero de 2017

Aceptado: 19 de julio de 2017 